\title{
La Ruralidad Chilena Actual. Aproximaciones desde la Antropología editado por Roberto Hernández Aracena y Luis Pezo Orellana. Colibris, Santiago, 2010, pp. 388.
}

\section{Comentado por Debbie Guerra Maldonado ${ }^{1}$}

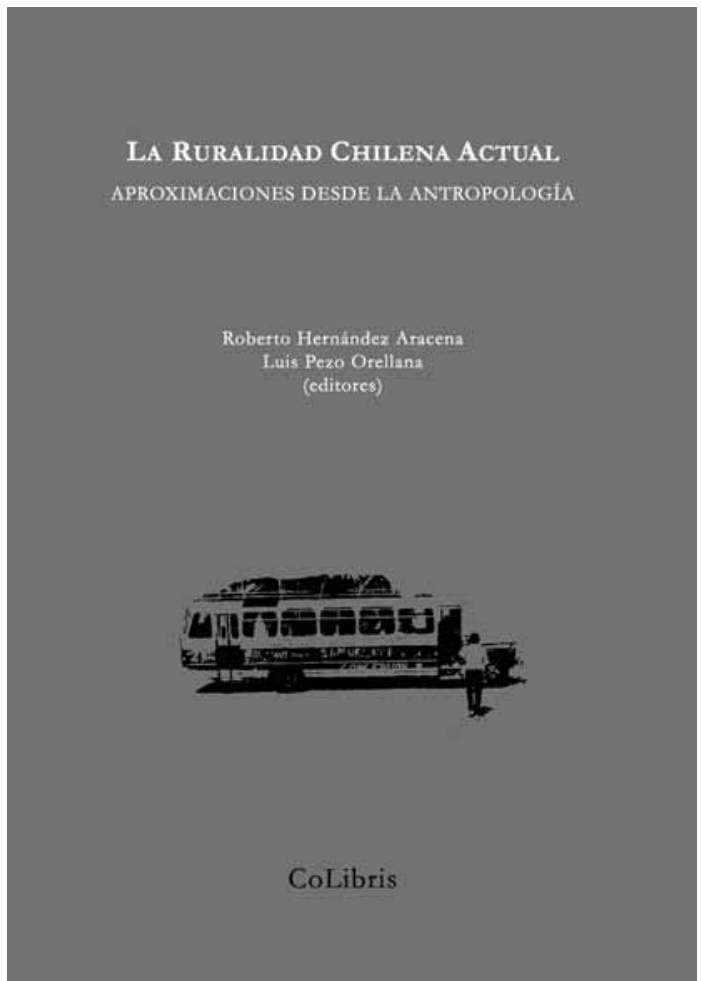

Lo que ocurre a la antropología rural es lo que, desde cierta perspectiva, suele pasar con la ruralidad: se homogeneiza y se invisibiliza. El sujeto rural desaparece. Esta desaparición no es inocente y representa opciones políticas declaradas, ante las cuales la antropología rural debiera pronunciarse. Para ilustrar este argumento voy a citar una opinión publicada en el Diario La Segunda del día 19 de octubre de 2010 sobre las políticas rurales, de Ronald Fischer, Profesor Titular de la Universidad de Chile, del Centro de Economía Aplicada del Departamento de Ingeniería Industrial, que, en parte, representa lo que pueden ser las orientaciones generales actuales del Estado chileno.

Fischer se pregunta: ¿Por qué debemos subsidiar a los pobladores rurales para que sigan viviendo en esos parajes? Su reflexión parte de la base según la cual la mayor parte de los/as habitantes rurales se dedican, desde su punto de vista, a una agricultura ineficiente, lo que les mantiene en condiciones de pobreza y de precariedad educacional. Los/as habitantes rurales, desde su perspectiva, son un peso para el sector público y su continuidad en los territorios es una prolongación de su pobreza.

¿Qué hacer?, se pregunta Fischer (2010). Plantea que las políticas rurales debieran estimular el éxodo hacia las ciudades, donde finalmente los empobrecidos habitantes rurales puedan encontrar la esquiva modernidad. Es en la ciudad donde podrán acceder a niveles de vida y educación aceptables. Lo que en consecuencia se requiere es transformar los subsidios rurales en subsidios a la movilidad. El argumento de Fischer (2010) importa consecuencias políticas no menores como, por ejemplo, que las políticas de tierras en el mundo indígena sean consideradas como erróneas: "Lo que se necesita es facilitar la transición a las ciudades y no entregar tierras que los mantengan en la pobreza porque son bienes que no se pueden vender" (Fischer 2010:21).

El libro La Ruralidad Chilena Actual. Aproximaciones desde la Antropología, una colección de artículos editados por Hernández y Pezo (2010) invita a matizar los planteamientos de Fischer, los que, en resumen, representan, por una parte, una afirmación tácita de una cierta forma de concebir lo rural, y, por la otra, una ceguera absoluta acerca de las especificidades de la ruralidad en nuestro país. El libro convoca, en este sentido, a ver lo que la política propuesta prefiere no ver: el mundo rural en su especificidad histórica, en su diversidad y en su posible protagonismo. La otra mirada, que es la mirada del libro, prefiero presentarla en relación con tres ejes de reflexión que surgen de la lectura de los trece artículos y la presentación que contienen las 388 páginas de la obra. Estos ejes son los de la subordinación de lo rural, su pluralidad, y la definición de su significado.

\section{Subordinación Excluyente y el Verticalismo en la Relación con lo Urbano}

Autores como Hernán Salas y Juan Carlos Rodríguez (en Hernández y Pezo 2010:45-78) invitan a revisar estas decisiones de orientación racional de máximo resultado y de máxima eficacia que están implicadas en el artículo de Fischer (2010). Los autores sugieren que existe una expansión del nuevo dominio de la acción racional, donde el espacio se plantea como un campo de acción instrumental específico, articulando de modo significativo el planeamiento de la ocupación humana. Una mirada

$1 \quad$ Instituto Salud Sexual y Reproductiva y Centro de Estudios Ambientales y Desarrollo Humano Sostenible. Universidad Austral de Chile, Valdivia, Chile. guerradebbie@ gmail.com 
como esta prescinde de la consideración del territorio como socialmente constituido y con ello renuncian a dos aspectos que son centrales: el territorio como espacio social apropiado y como espacio valorado.

El espacio es donde se desarrolla la identidad y se ejerce la pertenencia de los sujetos, dentro de un contexto que diferencia las formas de apropiación y valorización de cada grupo, de acuerdo con lo que el grupo y su cultura son: el territorio se define dentro de las estrategias patrimoniales de éste (Salas y Rodríguez en Hernández y Pezo 2010:69).

La lectura invita a recuperar no sólo la particularidad de las distintas escenas rurales, sino que también a aventurarse en el protagonismo siempre postergado de sus sujetos y a embarcarse en un imaginario que les permita permear las relaciones con el Estado y con el medio extralocal.

\section{Pluralidad de los Mundos Rurales, Identidad y Sujeto}

En la mirada oficial prima el esencialismo inspirado por el congelamiento metonímico a través del que se hace desaparecer la presencia del sujeto (Clifford 1999 [1997]). En la lectura oficial se congela e invisibiliza, por ejemplo, la importancia de la participación económica de las mujeres, acentuándose el sesgo patriarcal de la sociedad chilena. Se ignora, en ese enfoque, el control de las mujeres sobre los procesos de producción y participación, plantean Andrea Chamorro, Juan Pablo Donoso y Rafael Contreras (en Hernández y Pezo 2010), a lo que se podría agregar su contribución a la conservación de la biodiversidad por la vía del manejo de las semillas. En Río Hurtado, sugieren la autora y los autores recién citados, las instituciones públicas no reconocen a las mujeres como sujetos de proyectos productivos, de modo que el modelo de desarrollo impulsado desde el Estado las excluye, negando su participación efectiva en la economía local.

La contribución de Sergio González (en Hernández y Pezo 2010:111-134) abre un espacio importante para el ejercicio de la ciudadanía desde lo rural, rescatando de paso la posibilidad de entender lo rural como un estilo de vida abierto donde no se renuncia a la superposición de los contenidos urbano-rurales y que, por lo tanto, no está definido por lo puramente negativo o residual. En la compleja relación entre la identidad y la ciudadanía, leída en un artículo del autor, se abre la posibilidad de, al modo que lo plantea Anzaldúa (1999), vivir en la frontera (borderlands).

Este espacio de protagonismo y ciudadanía permite a Yanko González (en Pezo y Hernández 2010:201-232) y a Luis Pezo Orellana (en Pezo y Hernández 2010:179200) romper con el adultocentrismo de la antropología y del proyecto nacional urbano al considerar a las y los jóvenes rurales como sujetos, analizando sus dislocaciones y resignificaciones, con metodologías participativas. A su vez, Andrés Donoso (en Hernández y Pezo 2010:277-290) fija su atención en el papel efectivo de las organizaciones en los procesos de toma de decisión y advierte el debilitamiento de la sociedad civil. La riqueza de cada organización no se logra verter en perspectivas propias que las inviten como proponedoras y, por qué no, como implementadoras de políticas de desarrollo ajustadas a su dinámica y especificidad.

Sin embargo, la obra en comento plantea precaución respecto de las formas en cómo se canaliza la participación de los sectores rurales en las políticas públicas. La paradoja es que la participación implica su propia negación. Así se desprende de la lectura del texto de Marcelo González (en Hernández y Pezo 2010: 253-276), cuando se necesitan representantes, pero no se admite la representación. Es la necesidad de representantes que plantea la legislación chilena lo que condiciona, en el mundo indígena, la generación de tales representaciones, con lo que, junto con tensionar las relaciones locales, se impide permear desde lo rural-indígena la política pública. Se trata de políticas que buscan crear dirigentes para administrar el imaginario público.

\section{Los Significados de la Ruralidad}

Para Fischer (2011) la ruralidad, en lo social, tiene una connotación puramente negativa, y en lo económico, tiene un sentido puramente extractivo. Pero ¿qué se entiende por ruralidad? ¿Qué se quiere con ella y sus habitantes? Gonzalo Díaz Crovetto (en Hernández y Pezo 2010:79-110) invita a historizar los conceptos generados acerca de la ruralidad y con ello concretar o especificar los procesos en su complejidad. ¿Qué es lo que vale del medio rural? ¿El suelo explotable, el material extraíble, las especies depredables? ¿O bien es el paisaje, el valor ecológico, el sentido identitario o patrimonial? Lo rural, así visto, no es puramente residual y la especificación de la condición rural resulta urgente frente a la pura negatividad y subordinación con que, desde la postura oficial, se lo planea con su consiguiente destrucción.

Roberto Hernández y Carlos Thomas (en Hernández y Pezo 2010:135-178) plantean un modelo ecológico cultural para la educación rural, que permita avanzar en su especificación, integrando la dimensión ambiental para fomentar fórmulas cooperativas que rescaten valores comunitarios como la solidaridad y la cooperación y fortalezcan los sistemas sociales locales, protegiendo además los bienes patrimoniales. La educación rural implica recuperar la complejidad local para ponerla al servicio de estos propósitos.

En suma, podría concluirse, de acuerdo con lo planteado por Vanessa Rojas, que en términos de sus significados lo rural sigue siendo configurado a partir de los ojos citadinos, provocando una relación unilateral entre el campo y la ciudad, primando ante todo la construcción de significados desde la perspectiva urbana (en Hernández y Pezo 2010:235). 
Ello se traduce en lo que, desde la perspectiva de Hernández y Pezo (2010:16), se describe como el proceso de conformación de la llamada nueva ruralidad "signada por la imposición de un modelo de desarrollo hacia fuera, a pesar de las resistencias de varios sectores excluidos de este proceso". Esta imposición queda de manifiesto en la situación actual de la economía caprina tradicional, cuya obstinada insistencia en formas tradicionales de producción la ha convertido en objeto de una intervención pública -consistente con la lectura oficial propuesta por Fischer (2011) - orientada más a su extinción que a su desarrollo, como se desprende de la lectura de Stüdemanm (en Hernández y Pezo 2010:325-366).

Lo rural, en contraposición a la versión oficial que inspira a la política pública, reclama ser visto en su complejidad e intersección con el mundo urbano y global. Se trata de soluciones heterogéneas, generadas por actores diversos y diversas, que dan cuenta de modos de habitar el territorio a través de los que se preserva una buena parte de la naturaleza y los patrimonios. Estos modos reclaman visibilidad no sólo para su mera reproducción, sino para hacerse presente mediante una representación efectiva en los procesos de toma de decisión que les afectan directamente, como se sugiere en este libro.

Esta constatación impone el desafío al quehacer de la antropología rural de "reducir la fragmentación y dispersión del quehacer académico y profesional", a fin de realizar aportes significativos ... que favorezcan concretamente a las diversas poblaciones rurales" (Hernández y Pezo 2010:36-37).

Terminaré señalando que este libro marca varios hitos importantes para la antropología chilena: es el primer libro patrocinado por el Colegio de Antropólogos de Chile A.G. $\mathrm{Su}$ factura cuidadosa y extensa demuestra la dedicación y entrega de sus editores, Roberto Hernández Aracena y Luis Pezo Orellana. El libro representa, además, uno de los pocos compendios de antropología chilena cuya prolijidad y exhaustividad lo convierten en un referente obligado para estudiantes, investigadores/as, investigados/as y la comunidad en general. El volumen de la producción compilada por el libro habla de la vigencia de una reflexión importante, que permite sugerir que la antropología rural, lejos de de ser un tema agotado, es, como señalaba el lema del VII Congreso Chileno de Antropología (2010), una apertura a nuevos desafíos en la disciplina.

Las tareas planteadas por la propia obra a través de las reflexiones de sus editores invitan a identificar elementos diferenciadores del mundo rural, a fortalecer el desarrollo teórico en sus procesos de cambio y avanzar en los niveles de consolidación disciplinaria. Algunas preguntas siguen rondando: los temas de la exclusión, las relaciones de género e intergeneracionales, las migraciones estacionales y la naturaleza de la interfaz urbano-rural (incluyendo el impacto de lo global, el turismo y los nuevos estilos de unidades asociadas a la producción orgánica), son materias que convocarán por mucho tiempo a este destacado grupo de investigadores e investigadoras que representan prácticamente a todas las generaciones de la antropología chilena.

Celebramos el nacimiento de este libro no sólo porque nos reúne como comunidad antropológica, sino también porque es un testimonio profundo de la existencia de un sector de la sociedad que Chile pareciera preferir ignorar.

\section{Referencias Citadas}

Anzaldúa, G. 1999. Borderlands/La Frontera. The New Mestiza. Aunt Lute Books, San Francisco.

Clifford, J. 1999 [1997]. Itinerarios Transculturales. Traducido por Mireya Reilly de Fayard. Gedisa, Barcelona.
Fischer, R. 2010. Opinión: Políticas Rurales. Diario La Segunda (19 octubre 2010: 21).

Hernández, R. y L. Pezo (eds.) 2010. La Ruralidad Chilena Actual. Aproximaciones desde la Antropología. Colibrís, Santiago. 



\section{Dataciones radiocarbónicas NO deberían demorar una eternidad}

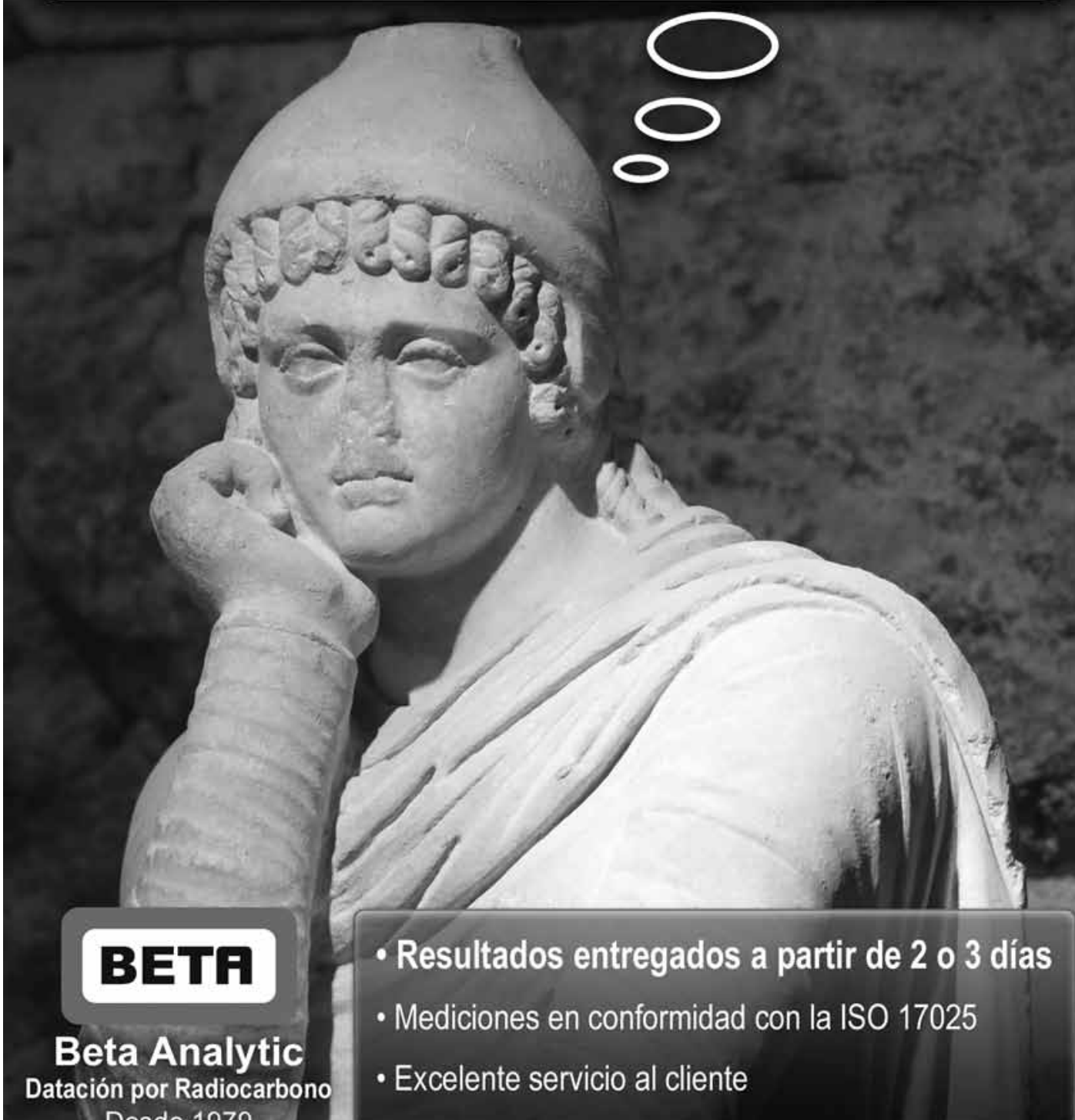

Desde 1979

\section{Australia Brasil China India Japón UK EE.UU} Visite www.radiocarbon.com para obtener detalles 

ANDROS IMPRESORES

www.androsimpresores.cl 
